\section{Infectious Bursal Disease: Evaluation of Maternal Immunity and Protection by Vaccination of One-Day Old Chicks Against Challenge with a Very Virulent Virus Isolate ${ }^{(3)}$}

- Author(s)
Moraes HLS1,2
Salle CTP1
Nascimento VP1
Salle FO'
Rocha ACGP1
Souza GF1
Furian TQ ${ }^{1}$
Artencio JO ${ }^{1}$
Centre for Diagnostics and Research in Avian
Pathology (CDPA).
2 College of Veterinary Medicine -
Universidade Luterana do Brasil (ULBRA).
3 Financial support from Conselho Nacional
de Desenvolvimento Científico e Tecnológico
(CNPq).

Mail Address

Hamilton Luiz de Souza Moraes College of Veterinary Medicine, UFRGS

Av. Bento Gonçalves, 8824

Bairro Agronomia

91.540-000. Porto Alegre, RS, Brazil

E-mail:hamilton.souza.moraes@ufgrs.br

Keywords

infectious bursal disease (IBD), very very virulent $\mathrm{IBD}$ virus, vaccination, maternal immunity.

\section{ABSTRACT}

Broiler chicks belonging to two poultry companies, A and B, with different breeders' vaccination programs were challenged with a very virulent strains of infectious bursal disease virus (vvlBDV), genotyped as G11. Birds were separated in four groups, two vaccinated at the first day of life and two unvaccinated. They were then challenged at the $1^{\text {st }}$, $4^{\text {th }}, 7^{\text {th }}, 10^{\text {th }}, 13^{\text {th }}, 16^{\text {th }}, 19^{\text {th }}$ and $22^{\text {th }}$ days. At every day of challenge, before and after the procedure, the following data were collected from each group: Bursa of Fabricius (BF) relative weight, BF diameter, BF for histologie examination, serum for measuring antibodies against IBDV through the ELISA and clinical evaluation of IBD.

The results obtained have shown a non-significant drop in antibody level between the vaccinated and the unvaccinated groups. When analyzing the different results, it could be established that an ELISA titre of 3,4 $\log 10$ was the cutoff point between healthy and sick birds. Regression equations were built to determinate the best moment for vaccination and also the ELISA log titre birds what could present in a given age. Based on that, chicks from Company $A$ should receive a vaccine against IBD from the $6^{\text {th }}$ to $7^{\text {th }}$ day of age, while the ones from Company $B$ should get it between the $11^{\text {th }}$ and the $12^{\text {th }}$ day of age.

Finally, the overall results suggest that the birds should not be vaccinated at one day old, and also that the breeders' different vaccination schemes resulted in progenies with different levels of maternal protection, and as a consequence the same vaccination plan should not be applied indiscriminately to broilers from different poultry companies.

\section{INTRODUCTION}

Infectious bursal disease (IBD), a highly contagious acute viral disease that affects growing chickens, was first described by Cosgrove (1962) and denominated Gumboro disease (GD). Winterfield et al. (1972) described that IBDV was infective, caused injuries and was persistent in chickens. Several studies have demonstrated that IBDV causes immunosupression. Sharma et al. (2000) described that IBDV impairs the humoral, cellular and innate immune responses when stimulated by the tetanus toxin and Brucella abortus. Clinical signs occur in 10 to $20 \%$ of the affected chickens and mortality reaches 10 to 20\% (Ley et al., 1983). IBD is endemic in the poultry industry and is considered one of the most important infectious diseases from the economic point of view (Shane et al., 1994). In 1997, highly virulent IBDV strains were detected in Brazil (Di Fabio et al., 1999), and since then have been causing high mortality and great economic losses to the poultry producers. Ikuta et al. (2001) analyzed 48 commercial poultry flocks using the Reverse Transcriptase Polymerase Chain Reaction (RT-PCR) and detected the 
Moraes HLS, Salle CTP, Nascimento VP, Salle FO, Rocha ACGP, Souza GF, Furian TQ, Artencio JO

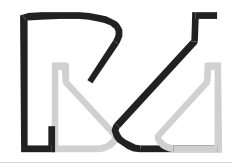

vaccine strain in 12 flocks, a classic strain in one flock, four new genotypic patterns in 31 flocks and one very virulent strain (also described in Europe and Asia) in four flocks.

IBDV is very stable and resistant to many disinfectants, and therefore vaccination is considered as the best way to control the disease (Van den Berg \& Meulemans, 1991). Breeders are hyperimmunized with live and inactivated vaccines in oil suspension in order to protect the progeny by the passive transfer of antibodies (Sharma et al., 1989). Naqi et al. (1983) reported that young chicks with high titers of maternal antibodies and vaccinated at 3 days of age with an intermediate vaccine did not develop a humoral immune response, even though these birds resisted to a later challenge with a classic strain of IBDV. Tsukamoto et al. (1995) evaluated three vaccines available in Japan and observed that one of them (intermediate type) protected almost $100 \%$ of the birds vaccinated at 20 days of age and challenged 10 days later with a very virulent IBDV strain. The authors suggested that the high levels of maternal antibodies play an important role in protection and that all flocks should be vaccinated according to adequate schedules. In practice, although different schedules of vaccination are recommended and used in Brazil, outbreaks outbreaks have been frequently reported.

This study was performed to evaluate the influence of maternal antibodies on the humoral immune response and on the protection provided by vaccination at one day of age in chicks challenged with a very virulent strain of IBDV isolated in Brazil.

\section{MATERIALS AND METHODS}

Birds: It was used 960 birds of a commercial strain and originated from IBD-vaccinated breeders belonging to two poultry companies ( $A$ and $B$ ). One day-old chicks from each company were divided in vaccinated and unvaccinated groups. Birds were fed ad libitum with a commercial diet that was supplied by the companies that collaborated with the experiment. Groups of vaccinated and unvaccinated birds were housed in separated cages and placed in different isolated rooms with positive pressure and filtered air flow.

Vaccination of the breeders against IBD: Company $A$ : on the $1^{\text {st }}$ day, an intermediate subcutaneous vaccine (Fort Dodge); on the $7^{\text {th }}$ day intermediate ocular (Fort Dodge); on the $42^{\text {nd }}$ day ocular intermediate; on the $77^{\text {th }}$ day intermediate (Biovet) via drinking water; and intramuscular inactivated vaccine
Infectious Bursal Disease: Evaluation of Maternal Immunity and Protection by Vaccination of One-Day Old Chicks Against Challenge with a Very Virulent Virus Isolate

in oil adjuvant (Biovet) on the $140^{\text {th }}$ day. Company B: intermediate ocular vaccine (Bur 706 Merial) on the $8^{\text {th }}$ day; on the $21^{\text {st }}$ day intermediate ocular (Bur 706 Merial); on the $35^{\text {th }}$ day intermediate via drinking water (Bur 706 Merial); on the $105^{\text {th }}$ day intermediate via drinking water (Bur 706 Merial); and on the 140 14 th day inactivated in oil adjuvant (Intervet) via intramuscular.

Chick vaccination: chicks from both companies were immunized with the intermediate vaccine Bursine $2^{\circledR}$ (Fort Dodge), which is produced from an attenuated Lukert strain. The vaccine was titered by chorioallantoic membrane inoculation (CAM) using specific pathogen free (SPF) embryos (Sadia SA, Uberlândia-MG). Titers calculated according to the method of Reed \& Muench (1938) were $10^{3.2} \mathrm{DI}_{50} / \mathrm{mL}$. One-day-old chicks were vaccinated via oculonasal with one dose of the vaccine divided in two drops.

Challenge inoculum: a strain of IBDV was isolated from the bursa of Fabricius (BF) of a naturally infected bird. The strain was characterized as a very virulent strain and identified by RT-PCR as genomic pattern 11 (G11), as described by Ikuta et al. (2001). This IBDV strain was called GAR-1 and used in the experiment. Thirty SPF birds were inoculated with GAR-1 at 21 days old and then housed in an isolation unit with positive pressure and filtered airflow. During the period between 3 and 7 days after inoculation, BF from dead and sick birds were collected and macerated with sterile sand and phosphate buffered saline (PBS). After centrifugation in a Sorvall Super $T$ refrigerated centrifuge, the pellet was resuspended in $100 \mathrm{~mL}$ of PBS and kept at $-80{ }^{\circ} \mathrm{C}$. Chicken infectious anaemia virus and reovirus were not detected in the bursas from GAR-1-inoculated birds by PCR (Simbios Produtos Biotecnológicos Ltda). Suspensions were titered using CAM in SPF embryonated eggs and the inoculum was prepared at a concentration of $10^{4} \mathrm{DI}_{50} / \mathrm{mL}$, according to Nunoya et al. (1992). This inoculum was administered to $20 \mathrm{SPF}$ birds $\left(10^{4} \mathrm{DI}_{50} / \mathrm{mL}\right)$, and the in vivo pathogenicity of the virus was assessed until 7 days after inoculation.

Challenge: Twenty birds from each group were challenged via ocular at every three days from 1 to 22 days of age using the GAR-1 sample $(50 \mu \mathrm{L}$ in each eye). Bursas of Fabricius and blood were collected 5 days after each challenge. Besides, 10 birds per experimental group were killed before each challenge and the bursas of Fabricius were sampled and used as control.

Serology: sera from 20 birds per group were collected 5 days after each challenge and antibodies 
Moraes HLS, Salle CTP, Nascimento VP, Salle FO, Rocha ACGP, Souza GF, Furian TQ, Artencio JO against IBDV were measured using a commercial ELISA kit (CIVITEST ${ }^{\mathrm{TM}}$ AVI IBD ${ }^{\circledR}$, Laboratórios Hipra, S.A.).

Diameter of the bursa of Fabricius: a total of 30 bursas of Fabricius per group (20 challenged and 10 control birds) were submitted to diameter qualitative measurement and given scores from 1 to 8 , based on the following parameters: score $1=$ diameter up to $3.17 \mathrm{~mm}$; score $2=$ from 3.17 to $6.35 \mathrm{~mm}$; score $3=$ from 6.35 to $9.52 \mathrm{~mm}$; score $4=$ from 9.52 to 12.70 $\mathrm{mm}$; score $5=$ from 12.70 to $15.87 \mathrm{~mm}$; score $6=$ from 15.87 to $19.05 \mathrm{~mm}$; score 7 = from 19.05 to 22.22 $\mathrm{mm}$; and finally score $8=$ from 22.22 to $25.40 \mathrm{~mm}$. For standardization purposes, it was used a ruler that contains orifices with different diameters equal to the superior limits of each score (Bursometer, kindly supplied by Fort Dodge Brazil).

Bursa of Fabricius' Relative weight (BFRW): a total of 30 chickens from each group (20 challenged and 10 controls) were weighed, sacrificed and necropsied. The bursas were sampled and weighed. The ratio between the bursa of Fabricius weight and body weight was calculated using the following formula: bursa weight divided by body weight multiplied by 1000 (BW/ BBW x 1000).

Histology: The 30 bursas of Fabricius were fixed in $10 \%$ phosphate-buffered formalin. Transversal histological cuts from the median region were stained with hematoxylin-eosin (HE) and microscopically analyzed. The depletion degree of the lymphoid tissue in the bursas was evaluated by microscopy and scored from 0 to 5 , where $0=$ normal $B F, 1=<25 \%$ of lymphoid depletion, $2=25-50 \%$ of lymphoid depletion, $3=50$ $70 \%$ of lymphoid depletion, $4=70-90 \%$ of lymphoid depletion and $5=>90 \%$ of lymphoid depletion, according to Muskett et al. (1979).

IBD evaluation: birds were considered infected when macroscopic alterations such as oedema and presence of gelatin-like exsudate on the serosa were seen at necropsy or when histological alterations with scores higher than 3 were observed in the bursa of Fabricius.

Statistical analyses: the results are expressed as means and standard deviation and were analyzed using the Sigmastat Statistical Sofware Version 2.0 (SPSS, Inc.) and Minitab ${ }^{\mathrm{TM}}$ Statistical Software Version 13.2 (Minitab, Inc.).

\section{RESULTS}

SPF birds inoculated with the viral suspension used in the experiment presented oedema and gelatin like
Infectious Bursal Disease: Evaluation of Maternal Immunity and Protection by Vaccination of One-Day Old Chicks Against Challenge with a Very Virulent Virus Isolate

exsudate deposited on the serosa in the bursa of Fabricius or histological alterations with score 5 . Five unchallenged control birds had no macro and microscopic injuries and BF histological score was 1.

According to Table 1, mean antibody titers were not different between vaccinated and unvaccinated birds. On the other hand, within the same treatment groups, there were differences between companies.

\begin{tabular}{|c|c|c|c|}
\hline \multicolumn{4}{|c|}{$\begin{array}{l}\text { Table } 1 \text { - Average ELISA titers }\left(\log _{10}\right) \text { of maternal } \\
\text { before challenge in birds grouped according to } \\
\text { (vaccinated or unvaccinated) and company (A or B). }\end{array}$} \\
\hline & $\mathbf{Y}$ & $\mathbf{s}$ & $\mathbf{n}$ \\
\hline Treatment Vaccinated & $3.00 * a$ & 0.78 & 149 \\
\hline Unvaccinated & $3.03^{a}$ & 0.73 & 149 \\
\hline Company $A$ & $2.87^{a}$ & 0.78 & 152 \\
\hline B & $3.17^{b}$ & 0.69 & 146 \\
\hline
\end{tabular}

Regression equation: There was a decline in maternal antibodies and results are shown in Tables 2 , 3, 4 and 5. Two regression equations were generated for each company using the ELISA mean titers of vaccinated and unvaccinated birds from the first to the eighth challenge:

Company A: Elisa titer $\left(\log _{10}\right)=3.47+(0.0303 \times$ age $)-$ $\left(0.00457 \times\right.$ age $\left.^{2}\right)$

$R^{2}=96.0 \% \quad R=96.5 \% \quad n=8$

Age $=-13.4+\left(34.1 \times\right.$ Elisa titer $\left.\left(\log _{10}\right)\right)-(8.32 \times($ Elisa titer $\left.\left(\log _{10}\right)^{2}\right)$

$\mathrm{R}^{2}=84.8 \% \quad \mathrm{R}=85.7 \% \quad \mathrm{n}=8$

Company B: Elisa titer $\left(\log _{10}\right)=3.71+(0.0144 \times$ age $)-$ $\left(0.00335 \times\right.$ age $\left.^{2}\right)$

$\mathrm{R}^{2}=86.1 \% \quad \mathrm{R}=88.0 \% \quad \mathrm{n}=8$

Age $=-26.7+\left(43.1 \times\right.$ Elisa titer $\left(\log _{10}\right)-(9.39 \times$ (Elisa titer $\left.\left(\log _{10}\right)^{2}\right)$

$R^{2}=94.1 \% \quad R=94.9 \% \quad n=8$

Responses before and after challenge: Results of bursa parameters (diameter, relative weight, histological injuries), antibody titers (AGT) measured by ELISA and clinical assessment of the disease in the vaccinated and unvaccinated birds from company $A$ are presented in Tables 2 and 3. Results from company $B$ are shown in Tables 4 and 5 .

Histology of the Bursa of Fabricius: the evaluation of microscopic injuries before each challenge showed that vaccinated birds had lesion scores up to 3 , whereas all unvaccinated birds had scores lower 
Moraes HLS, Salle CTP, Nascimento VP, Salle FO, Rocha ACGP, Souza GF, Furian TQ, Artencio JO
Infectious Bursal Disease: Evaluation of Maternal Immunity and Protection by Vaccination of One-Day Old Chicks Against Challenge with a Very Virulent Virus Isolate than 1. After challenge, scores ranged from 2 to 5 according to the age at challenge, irrespective of whether or not the birds were vaccinated. Based on these results, birds were considered protected if scores were up to 3 , and sick when scores were higher than 3, as shown in Tables 2, 3, 4 and 5.

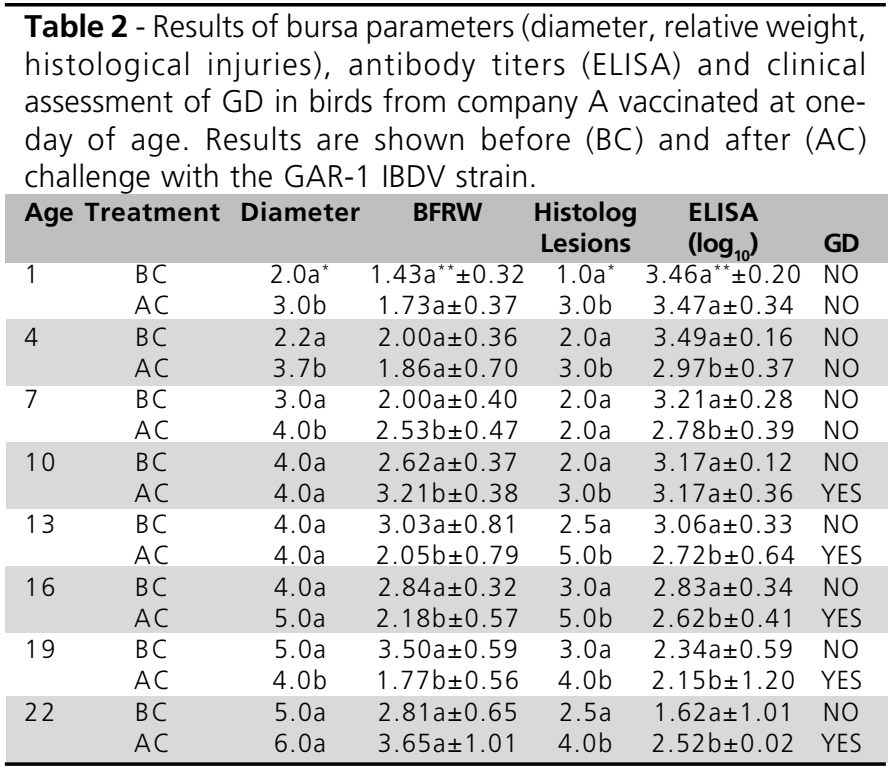

*Median - Mann Whitney Rank Sun Test. ** Mean - $t$ test. In each challenge day, $B C$ and $A C$ means followed by different letters are significantly different $(p<0.05)$. BFRW $=$ Bursa of Fabricius Relative Weight. Histolog Lesions= Histological Lesions index. GD= Gumboro Disease.

Table 3 - Results of bursa parameters (diameter, relative weight, histological injuries), antibody titers (ELISA) and clinical assessment of GD in unvaccinated birds from company $A$. Results are shown before $(B C)$ and after $(A C)$ challenge with the GAR-1 IBDV strain.

\begin{tabular}{|c|c|c|c|c|c|c|}
\hline \multicolumn{2}{|c|}{ Age Treatment } & Diameter & BFRW & $\begin{array}{c}\text { Histolog } \\
\text { Lesions }\end{array}$ & $\begin{array}{l}\text { ELISA } \\
\left(\log _{10}\right)\end{array}$ & GD \\
\hline \multirow[t]{2}{*}{1} & $B C$ & $2.0 a^{*}$ & $1.57 a^{* *} \pm 0.30$ & $1.0 a^{*}$ & $3.52 a^{\star \star} \pm 0.22$ & NO \\
\hline & $A C$ & $3.0 \mathrm{~b}$ & $1.86 a \pm 0.70$ & $2.0 \mathrm{~b}$ & $3.47 a \pm 0.01$ & NO \\
\hline \multirow[t]{2}{*}{4} & $B C$ & $3.0 \mathrm{a}$ & $2.05 a \pm 0.41$ & $1.0 a$ & $3.50 a \pm 0.14$ & NO \\
\hline & $A C$ & $3.0 \mathrm{a}$ & $2.25 a \pm 0.61$ & $2.0 \mathrm{~b}$ & $2.97 b \pm 0.37$ & NO \\
\hline \multirow[t]{2}{*}{7} & $B C$ & $3.0 \mathrm{a}$ & $1.82 a \pm 0.49$ & $1.0 \mathrm{a}$ & $3.30 a \pm 0.42$ & NO \\
\hline & $A C$ & $3.0 \mathrm{a}$ & $2.22 \mathrm{a} \pm 0.37$ & $2.0 \mathrm{~b}$ & $2.23 b \pm 1.39$ & NO \\
\hline \multirow[t]{2}{*}{10} & $B C$ & $3.0 \mathrm{a}$ & $2.08 a \pm 0.47$ & $1.0 \mathrm{a}$ & $3.11 \mathrm{a} \pm 0.62$ & NO \\
\hline & $A C$ & $4.0 b$ & $3.07 b \pm 1.12$ & $2.0 \mathrm{~b}$ & $3.17 \mathrm{a} \pm 0.30$ & YES \\
\hline \multirow[t]{2}{*}{13} & $B C$ & $4.0 a$ & $2.35 a \pm 0.51$ & $1.0 a$ & $3.05 a \pm 0.46$ & NO \\
\hline & $A C$ & $4.0 \mathrm{a}$ & $2.29 a \pm 0.65$ & $4.0 \mathrm{~b}$ & $2.09 b \pm 0.98$ & YES \\
\hline \multirow[t]{2}{*}{16} & $B C$ & $4.0 a$ & $2.86 a \pm 0.88$ & $1.0 a$ & $2.72 a \pm 0.25$ & NO \\
\hline & $A C$ & $4.0 \mathrm{a}$ & $2.13 a \pm 1.21$ & $4.0 b$ & $2.62 a \pm 1.17$ & YES \\
\hline \multirow[t]{2}{*}{19} & $B C$ & $4.4 \mathrm{a}$ & $2.84 a \pm 0.43$ & $1.0 a$ & $1.98 a \pm 0.57$ & NO \\
\hline & $A C$ & $3.8 a$ & $1.58 b \pm 0.92$ & $5.0 b$ & $2.96 b \pm 0.47$ & YES \\
\hline \multirow[t]{2}{*}{22} & $B C$ & $5.0 a$ & $2.79 a \pm 0.69$ & $1.0 a$ & $1.23 a \pm 1.02$ & NO \\
\hline & $A C$ & $5.0 a$ & $2.49 a \pm 0.90$ & $4.0 \mathrm{~b}$ & $3.03 b \pm 0.25$ & YES \\
\hline
\end{tabular}

*Median - Mann Whitney Rank Sun Test. ** Mean - $t$ test. In each challenge day, $B C$ and $A C$ means followed by different letters are significantly different $(p<0.05)$. BFRW $=$ Bursa of Fabricius Relative Weight. Histolog Lesions= Histological Lesions index. GD= Gumboro Disease.

Diameter: there were no significant differences in the diameter of the bursa between vaccinated and unvaccinated birds before challenge at most ages (1, $4,7,13,16$ and 22 days). Significant differences were seen only at 10 and 19 days old. BF diameter results after challenge days were very labile, and no conclusive analysis was possible (Tables 2, 3, 4 and 5).

\begin{tabular}{|c|c|c|c|c|c|c|}
\hline \multicolumn{7}{|c|}{$\begin{array}{l}\text { Table } 4 \text { - Results of bursa parameters } \\
\text { histological injuries), antibody tit } \\
\text { assessment of GD in birds from comp } \\
\text { day of age. Results are shown bef } \\
\text { challenge with the GAR-1 IBDV strain }\end{array}$} \\
\hline Age & Treatment & Diameter & BFRW & $\begin{array}{l}\text { Histolog } \\
\text { Lesions }\end{array}$ & $\begin{array}{l}\text { ELISA } \\
\left(\log _{10}\right)\end{array}$ & GD \\
\hline \multirow[t]{2}{*}{1} & $B C$ & $2.0 a^{*}$ & $1.68 a^{\star \star} \pm 0.40$ & $1.0 a^{*}$ & $3.70 a^{\star \star} \pm 0.41$ & NO \\
\hline & $A C$ & $3.0 \mathrm{~b}$ & $2.06 a b \pm 0.21$ & $2.0 \mathrm{~b}$ & $3.29 a \pm 1.36$ & NO \\
\hline \multirow[t]{2}{*}{4} & $B C$ & $2.0 a$ & $2.19 a \pm 0.69$ & $2.0 a$ & $3.76 a \pm 0.13$ & NO \\
\hline & $A C$ & $3.0 \mathrm{a}$ & $2.17 a \pm 0.74$ & $2.7 b$ & $3.07 b \pm 0.31$ & NO \\
\hline \multirow[t]{2}{*}{7} & $B C$ & $3.0 \mathrm{a}$ & $2.47 a \pm 0.52$ & $2.0 a$ & $3.54 a \pm 0.20$ & NO \\
\hline & $A C$ & $4.0 \mathrm{a}$ & $2.72 \mathrm{a} \pm 0.73$ & $3.0 \mathrm{~b}$ & $3.28 b \pm 0.34$ & NO \\
\hline \multirow[t]{2}{*}{10} & $B C$ & $3.5 a$ & $2.70 a \pm 0.60$ & $2.0 a$ & $3.43 a \pm 0.21$ & NO \\
\hline & $A C$ & $4.0 \mathrm{~b}$ & $2.68 a \pm 0.71$ & $2.5 b$ & $3.47 a \pm 0.16$ & NO \\
\hline \multirow[t]{2}{*}{13} & $B C$ & $4.0 a$ & $3.07 a \pm 0.53$ & $2.5 a$ & $3.27 a \pm 0.33$ & NO \\
\hline & $A C$ & $4.0 \mathrm{a}$ & $2.23 b \pm 0.52$ & $4.0 \mathrm{~b}$ & $2.89 b \pm 0.32$ & YES \\
\hline \multirow[t]{2}{*}{16} & $B C$ & $4.3 a$ & $3.09 a \pm 0.37$ & $3.0 \mathrm{a}$ & $3.23 a \pm 0.17$ & NO \\
\hline & $A C$ & $5.0 b$ & $2.97 a \pm 0.99$ & $5.0 \mathrm{~b}$ & $0.566 a \pm 1.19$ & YES \\
\hline \multirow[t]{2}{*}{19} & $B C$ & $5.0 a$ & $3.26 a \pm 0.58$ & $2.5 a$ & $2.80 a \pm 0.59$ & NO \\
\hline & $A C$ & $5.0 a$ & $2.87 a \pm 1.20$ & $4.5 b$ & $2.29 b \pm 0.85$ & YES \\
\hline \multirow[t]{2}{*}{22} & $B C$ & $4.9 a$ & $3.23 a \pm 0.39$ & $2.8 a$ & $1.12 a \pm 0.12$ & NO \\
\hline & $A C$ & $6.1 \mathrm{~b}$ & $3.22 \mathrm{a} \pm 1.06$ & $4.2 b$ & $2.39 b \pm 0.42$ & YES \\
\hline
\end{tabular}

*Median - Mann Whitney Rank Sun Test. ** Mean - t test. In each challenge day, $B C$ and $A C$ means followed by different letters are significantly different $(p<0.05)$. BFRW $=$ Bursa of Fabricius Relative Weight. Histolog Lesions= Histological Lesions index. GD= Gumboro Disease.

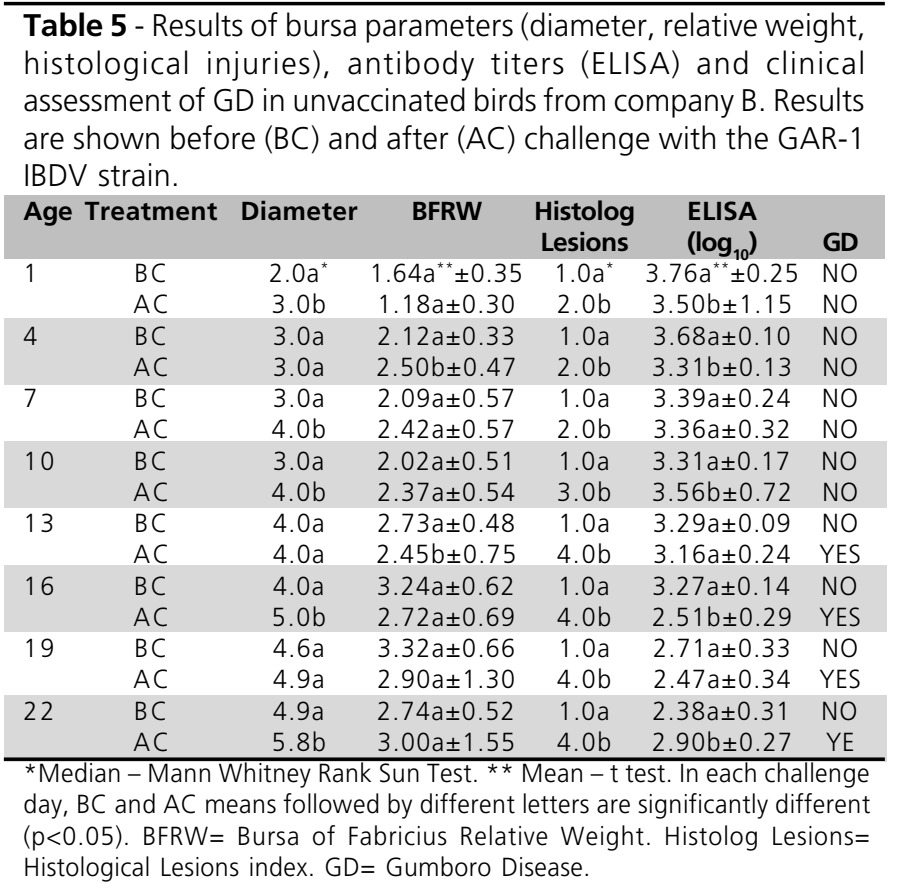

Bursal relative weight: BFRW before challenge was significantly different between companies only between the $10^{\text {th }}$ and the $19^{\text {th }}$ day. After challenge, 
Moraes HLS, Salle CTP, Nascimento VP, Salle FO, Rocha ACGP, Souza GF, Furian TQ, Artencio JO irrespective of company, results were very labile, i.e., differences were significant in some challenge days but non significant in others. There was a decreasing tendency in the relative size from the $5^{\text {th }}$ challenge on, when compared to control birds (Tables 2, 3, 4 and 5).

\section{DISCUSSION AND CONCLUSIONS}

The injuries found in inoculated SPF chickens have demonstrated that the field sample used to challenge the birds was able to induce typical IBD injuries. Circulating antibodies before challenge reduced progressively both in vaccinated and unvaccinated birds until 22 days of age, corroborating results from other studies that have reported a similar behavior. Knoblich et al. (2000), Alam et al. (2002), Knezevic et al. (1999) concluded that vaccination does not accelerate the decrease in maternal antibodies if chicks are vaccinated at one day of age. Similarly to results reported by Knezevic et al. (1999), chicks with passive immunity and vaccinated with an intermediate IBDV strain in the first day of age showed no increase in antibody titers. Nevertheless, when vaccination was performed at 14 days, an increase in titer was observed. Kumar et al. (2000) reported similar conclusions using a quantitative agar gel precipitation test. Ahmed \& Akhter (2003) described a decrease in maternal antibodies and suggested an equation to estimate maternal antibody levels and establish the age until which the birds would be protected against field virus samples. In the experiment, these authors reported no mortality in a group of birds challenged until 14 days of age, suggesting that the maternal antibodies provided some level of protection up to that age. However, the degree of histological injury in the bursa of Fabricius was not mentioned.

The results of the present study showed that diameters varied from 2 to 6 according to the age of birds. Considering that there were similar histological injuries between control and challenged birds, independent of vaccination status and company, it seems that there is no relation between bursa diameter and presence of injuries caused by disease or vaccination. These findings corroborate results previously reported by Pereira (2002). In a previous study performed in our lab, broilers were vaccinated with different intermediary IBD vaccines and injury indexes could not be attributed to disease or vaccination based solely on bursa diameter; therefore, histological evaluation was also performed to give appropriate injury scores (Pereira, 2002). Based on
Infectious Bursal Disease: Evaluation of Maternal Immunity and Protection by Vaccination of One-Day Old Chicks Against Challenge with a Very Virulent Virus Isolate

these observations, it can be concluded that BF diameter measurement should not be used as a single parameter for disease diagnosis or in decisions related to the evaluation of vaccination programs. The measurement of BF diameter must be seen with caution and used only as an auxiliary method, rather than a definitive one.

When the relative weight of the bursa was analised, the data showed that the bursas of Fabricius had their relative weight equal or heavier after the challenge, until the beginning of the histological injuries considered as disease. After, it turns into equal or lighter than the controls. As the relative weight was calculated 5 days after the each challenge, it could be supposed that until the fourth challenge, the level of maternal antibodies decreased the infectious rate, increasing the inflammatory process time, making the bursas apparently heavier, since they were still in the oedema phase. After the fourth challenge, the virus would overcome the antibodies barrier and cause the injuries in a shorter time, presenting the atrophy phase, 120 hours after the challenge, and, therefore, reducing the bursa of Fabricius weight. Chickens challenged with a very virulent sample of the IBD virus isolated in Japan showed bursa atrophy as soon as 3 to 4 days after inoculation (Tsukamoto et al., 1992). These observations are similar to the findings of the present study experiment. However, Mazariegos et al. (1990) stated that the relative weight of the bursa of Fabricius was not a good indicator of IBD. The same conclusion is true for the bursa diameter. Thus, the use of one of these criteria alone cannot establish if the bird has IBD or is healthy, and whether it was vaccinated or not.

After the birds were challenged with the GAR-1 sample, it was considered as IBDV infection sign if the birds had average histological scores higher than 3 after the challenge and showed macroscopic alterations (edema). Vaccinated birds after the third and the fourth challenges showed scores higher than 3 , which were similar to the scores from unvaccinated birds. Mazariegos et al. (1990) assessed the effects of intermediate vaccine samples and reported lesion scores ranging between 1.4 in controls, and up to 4 in the vaccinated birds. Therefore, it was considered that the animals were protected until a histological score of 3 , which corresponded to the period between 7 and 10 days of age. Histological injuries were seen even when antibody titers were considered protective. In these situations, the existing injuries were less intense than the injuries seen in sick birds, results similar to those reported by Maas et al. (2001). Chicks with high 
Moraes HLS, Salle CTP, Nascimento VP, Salle FO, Rocha ACGP, Souza GF, Furian TQ, Artencio JO

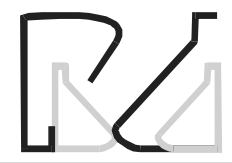

titers of maternal antibodies $\left(9 \log _{2}\right)$ measured by virus neutralization were challenged with either a classic viral strain (52/70) or with a very virulent strain of IBDV. The high titers of maternal antibodies prevented the clinical signs of the disease until 14 days of age, but not the damage in the bursa of Fabricius (Maas et al., 2001). If the birds were protected between the third and the fourth challenge, measured by histology, it is possible to use the mean of the ELISA titres, in these birds'age, as an indicator of the protection titre. The titre, in this occasion, was about $3,4 \log _{10}$ to vaccinated and unvaccinated birds. This way, it could be applied the regression equation, where in one of them the ELISA titre is an independent variable and the age the dependent one. The protective titre was chosen for being the highest $\left(3,21 ; 3,30 ; 3,43\right.$ e $\left.3,31 \log _{10}\right)$ capable of protecting the birds according to the experiment's working conditions. In the other, the titre is the dependent variable and the age the independent one, to establish until which age the animals would be protected or what titres the birds would have at a determined age. Solving the equation and establishing 3,4 $\log _{10}$ as the protective titre, the birds would be protected against the virus challenge until 6-7 days of age in the Company $A$ and until 11-12 days of age in the Company $\mathrm{B}$. These results demonstrate that the vaccination in the first day of life is not necessary; moreover, they show that the animals were protected during the first week of age. Therefore, the breeder vaccination program used in Company $B$ protects the progeny longer than the program used in Company $A$. The difference between the two vaccination programs clearly shows that failures may result if the age of the first vaccination is defined based solely on general models, as suggested by Kouwenhoven (1995) and Witt (2001), such as using the Deventer formula: Age= [square root (mean titer) - square root (target titer)]/ 2.82. When the values found in the present study are used in the Deventer formula, the expected values were not found. Factors such as correct breeder management practices, variations within flocks, and different vaccination programs and vaccine strains may also interfere in the results (Witt, 2001).

ELISA results were different between the two companies, which is according to expected, since they use different breeders' vaccination programs. Similar results were reported by Maas et al. (2001), who evaluated two inactivated oil vaccines against IBD and showed differences in relation to the maternal antibody levels and progeny protection against challenge with classic samples and very virulent samples of the IBD virus.
Infectious Bursal Disease: Evaluation of Maternal Immunity and Protection by Vaccination of One-Day Old Chicks Against Challenge with a Very Virulent Virus Isolate

The data from the present study permit to conclude that vaccinated and unvaccinated birds with antibodies titers higher than $3.4 \log _{10}$ in the first day of life were protected against the disease after challenge with the a very virulent strain of IBD. Besides, the histological findings in the bursas of Fabricius were compatible with the injuries shown previously to be induced by vaccination (Mazariegos et al., 1990). Chicks from hyperimmunized breeders do not need to be vaccinated on the first day of life. The age of vaccination must be determined using a regression equation specific for each company, because of differences between breeder vaccination programs and husbandry practices. In earlier studies, Salle (1989) challenged commercial chicks showing maternal antibodies with a classic sample of the virus (52/70) and also observed protection until 14 days of age, whereas Moraes et al. (1998) stated that vaccine strains were not antigenically different from field strains, and therefore other factors must be responsible for the difficulty in controlling the disease. Based on those results, the authors recommended that the vaccination schedule should follow an adequate planning, cleaning and disinfection of the environment, the choice of the best vaccine sample (Moraes, 2004), the field strains' typing (Sharma et al., 1989), the presence of mycotoxins (Azzam \& Gabal, 1998) and/or other diseases and the level of maternal antibodies. These factors are prone to influence the performance of the breeders vaccinations, as well as the broilers'.

\section{REFERENCES}

Ahmed Z, Akhter S. Role of maternal antibodies in protection against infectious bursal disease in Commercial Broilers. International Journal of Poultry Science 2003; 2(4):251-255.

Alam J, Rahman MM, Sil BK, Khan MSR, Sarker MSK. Effect of maternally derived antibody on vaccination against infectious bursal disease (Gumboro) with live vaccine in broiler. International Journal of Poultry Science 2002; 1(4):98-101.

Azzam AH, Gabal MA. Aflatoxin in layers hens. Avian Pathology 1998; 27(6):570-577

Cosgrove, AS. An apparently new disease of chickens: avian nefrosis. Avian Diseases 1962; 6: 385-389.

Di Fabio J, Rossini LI, Eterradossi N, Toquin MD, Gardin Y. Europeanlike pathogenic infectious bursal disease viruses in Brazil. Veterinary Record 1999; 145(7):203-204.

Ikuta N, El Attrache J,Villegas P, Garcia M, Lunge VR, Fonseca ASK, Oliveira C, Marques EK. Molecular caracterization of Brazilian infectious bursal disease viruses. Avian Diseases 2001; 45(2):297-306. 
Moraes HLS, Salle CTP, Nascimento VP, Salle FO, Rocha ACGP, Souza GF, Furian TQ, Artencio JO
Knezevic N, Sekler M, Veljovic LJ, Kozlina B, Rodic J. First experiences with poulvac R Bursine-2 vaccine against Gumboro disease. In: Proceedings of the $8^{\circ}$ Yogoslav Symposium on Poultry Production; 1999; Sokobanja, Yugoslavia.

Knoblich HV, Sommer SE, Jackwood DJ. Antibody titers to infectious bursal disease virus in broiler chicks after vaccination at one day of age with infectious bursal disease virus and Marek's disease virus. Avian Diseases 2000; 44:874-884.

Kouwenhoven B. El control de la enfermedad de gumboro muy virulenta em Holanda. World Poultry 1995; supl.:15-16.

Kumar K, Singh KCP, Prasad CB. Immune response to intermediate strain IBD vaccine at different levels of maternal antibody in broiler chickens. Tropical Animal Health and Production 2000; 32:357360 .

Ley DH, Yamamoto R, Bickford AA. The pathogenesis of infectious bursal disease: serologic, histopathologic, and clinical chemical observations. Avian Diseases 1983; 27:1060-1085

Maas RA, Venema S, Oei HL, Pol JMA. Claassen IJTM, Huurne HM. Efficacy of inactivated infectious bursal disease (IBD) vaccines: comparison of serology with protection of progeny chickens against IBD virus of varying virulence. Avian Pathology 2001; 30:345-354.

Mazariegos LA, Lukert, PD, Brown, J. Pathogenicity and Immunosuppressive Properties of Infectious Bursal Disease "Intermediate" Strains. Avian Diseases 1990; 34:203-208.

Moraes HLS, Salle CTP, Nascimento VP. Avaliação da relação antigênica e imunogênica entre amostras de campo e amostras vacinais do vírus da doença infecciosa bursal através do "western blotting". Pesquisa Agropecuária Gaúcha 1998; 4(1):73-83.

Moraes HLS. Doença Infecciosa Bursal: estudo sobre amostras vacinais, imunidade materna e desafio com amostra muito virulenta do vírus [tese]. Porto Alegre (RS): Universidade Federal do Rio Grande do Sul; 2004.

Muskett JC, Hopkins IG, Edwards KR, Thornton DH. Comparison of two infectious bursal disease vaccine strains: efficacy and potential hazards in susceptible and maternally immune birds. The Veterinary Records 1979; 14:332-334.

Naqi SA, Marquez B, Sabin N. Maternal antibody and its effect on infectious bursal disease immunization. Avian Diseases 1983; 27 (3):623-631.

Nunoya T, Otaki M, Hiraga M, Saito T. Occurrence of acute infectious bursal disease with high mortality in Japan and pathogenicity of field isolates in specific-pathogen-free chickens. Avian Diseases 1992; 36:597-609.

Pereira RA. Relação entre a população linfocitária bursal e o diâmetro da bolsa de Fabrício em frangos de corte [dissertação]. Porto Alegre (RS): Universidade Federal do Rio Grande do Sul; 2002,

Reed LJ, Muench H. A simple Method of Estimating Fifty Per Cent endpoints. American Journal of Hygiene 1938; 27:493-497.
Infectious Bursal Disease: Evaluation of Maternal Immunity and Protection by Vaccination of One-Day Old Chicks Against Challenge with a Very Virulent Virus Isolate

Salle CTP. Importância dos anticorpos maternos na doença de Gumboro. Avicultura e Suinocultura Industrial 1989; 957:112-114.

Sharma JM, Dohms JE, Metz AL. Comparative pathogenesis of serotype 1 and variant serotype 1 isolates of infectious bursal disease virus and their effect on humoral and cellular immune competence of specific-pathogen-free chickens. Avian Diseases 1989; 33:112124.

Sharma JM, Kim J, Rautenschlein S, Yeh HY. Infectious bursal disease virus of chickens: pathogenesis and immunosuppresion. Developmental and Comparitive Immunology 2000; 24:223-235.

Shane S, Lasher H, Paxton KW. Economic impact of infectious bursal disease. In: Proceedings of the $2^{\circ}$ International Symposium of Infectious Bursal Disease and Chicken Anaemia; 1994; Rauischholzhausen, Germany.

Tsukamoto K, Tanimura N, Hihara H, Shirai J, Imai K, Nakamura K, Maeda M. Isolation of virulent infectious bursal disease virus from field outbreaks with hight mortality in Japan. Journal Veterinary Medicine Science 1992; 54:153-155.

Tsukamoto K, Tanimura N, Kakita S, Ota K, Mase M, Imai K, Hihara $H$. Efficacy of three live vaccines against highly virulent infectious bursal disease virus in chickens with or without maternal antibodies. Avian Diseases 1995; 39 (2):218-229.

Van den Berg TP, Meulemans G. Acute infectious bursal disease in poultry: protection afforded by maternally derived antibodies and interference with live vaccination. Avian Pathology 1991; 20:409421.

Winterfield RW, Fadly AM, Bickford A. Infectivity and distribution of infectious bursal disease virus in the chicken: persistence of the virus and lesions. Avian Diseases 1972; 16(3):622-632.

Witt JJ. Gumboro Disease: estimation of optimal time of vaccination by the Deventer formula. In: Proceedings of the $3^{\circ}$ meeting of working group 3 of COST Action 839. Passive protection and vaccination (current and future possibilities) in the presence of maternally derived antibody; 2001; Pulawy, Poland. 